\title{
Internationalization \& the Rise of Knowledge Society: What Aspects Countries Need to Consider?
}

\author{
Meskerem Cheru Temtime \\ (Ass. Prof.) \\ Address: Olav M. Troviks Vei 18, Ho210 \\ Postal Code, 0864 Oslo
}

\begin{abstract}
The paper deals with important aspects countries need to consider in relation to internationalization $\&$ the rise of knowledge society. Along with this, three research questions such as What are the current patterns being observed in internationalization so far? What step must the government \& HEIS take in order to facilitate internationalization $\&$ a better place in the knowledge society? What are the assumed benefits $\&$ the known challenges? are raised $\&$ discussed. For a clear understanding of the paper as a whole, basic terminologies such as internationalization \& globalization, \& levels at which HE internationalization works are discussed briefly based on literature outcomes. Finally, concluding remarks were put in place.
\end{abstract}

\section{INTRODUCTION: BASIC CONCEPTS OF GLOBALIZATION \& INTERNATIONALIZATION}

According to Albatch (2006) in Altbach, Reisberg \& Rumbley (2009), globalization \& internationalization in $\mathrm{HE}$ refer to two distinct phenomena though frequently used interchangeably. Globalization typically makes reference to the broad trends that directly affect HE \& are largely inevitable in the contemporary world. On the other hand, internationalization is concerned with specific policies \& programs undertaken by governments \& academic systems as a whole to deal with globalization. One of the key distinctions between them is that globalization \& its effects are beyond the control of any actors. Internationalization, however, can be seen as a strategy for societies \& institutions to respond to the demands of globalization. Indeed, internationalization has been conceived as a process of integrating an international dimension in the purpose, \& functions of postsecondary education (Knight, 2003 in Altbach et al., 2009; Knight, 2012; Rumbly et al., 2012). These paradigms assure that the impact of HE has moved beyond national border (knight, 2008 in knight, 2013; Teichler, n.d).

\section{LEVELS AT WHICH HE INTERNATIONALIZATION FUNCTIONS}

According to Knight (2004b) in European Union (2015); Knight (2012), internationalization of HE consists internationalization at home \& internationalization abroad. The former consists of strategies \& approaches designed to inject an international dimension into the home campus experience like including global perspectives in the curriculum, recruiting international students, \& scholars. The later one calls for an institution to project itself \& its stakeholders out in the world by sending students to study abroad, setting up a branch campus, engaging in an international partnership (Altbach et al., 2009). Internationalization affects institutions, regions \& national systems of HE (Hénard, et al, 2012).

\section{Institutional \& National Level}

At institutional level, internationalization can be perceived as an expansion of missions, in many cases embracing service to a global community to produce global competencies. The 
establishment of international program, support offices \& the designation of staff time has become a commonplace in HEIs across the globe (Hénard et al., 2012). Meanwhile, internationalization of $\mathrm{HE}$ has reached the national agenda in a wide range of countries. Qatar, Singapore, \& the United Arab Emirates are countries promote internationalization as a matter of national policy. They recruit prestigious foreign universities to establish local campuses \& serves as HE hubs for their regions.

\section{Regional \& International Levels}

A focus on regionalization can also be seen in the establishment of such entities as the African Network for Internationalization of Education \& structured cooperation in order to promote the comparability of HE systems across the Mediterranean region (Catania Declaration, 2006 \& Teferra \& Knight, 2008 cited in Hénard et al., 2012). The declaration is to create HE Common Space in Southeast Asia. The inclusion of HE in the World Trade Organization's General Agreement on Trade in Services regime \& the Bologna process is another clear reflection of the way in which the international dimension of HE has achieved a global profile (Hénard, et al, 2012; Teichler, n.d).

\section{WHAT ARE THE CURRENT PATTERNS BEING OBSERVED IN INTERNATIONALIZATION SO FAR?}

As to Gornitzka, Gulbrandsen, Langfeldt (2008), the modes of internationalization has become more routinized, institutionalized \& systematic; No more individual based internationalization. Internationalization of HE manifested itself around the world in multiple ways. Although each local, national, \& regional context presents unique characteristics, several broad trends have been identified globally. These include mobility of people, programs, \& institutions; the rising prominence of collaborative research; evolving curricula as well as approaches to teaching \& learning; an increasingly heightened sense of the interconnectedness of the HE enterprise across the globe (Hénard, et al, 2012; Knight, 2012).

\section{International Mobility}

International mobility has become a central issue in HE. Mobility has a leading role in internationalization policies at different levels affecting a wide range of other policies \& practices in HE (Deardorff, 2014 in Sintayehu, 2014; Jacob \& Meek, 2013). International agreements between tertiary institutions that includes faculty exchange, international scholarship programs along with other collaborative projects, recruitment of academic superstars, professional meetings \& conferences (European Commission, 2008 in Hénard, et al, 2012; Teichler, n.d) become quite common. Mobility has not been limited to people; numbers of programs \& institutions are operating internationally by establishing sister institutions \& branch campuses of parent institutions and offering single filed of study jointly (Hénard et al, 2012).

\section{Commercialization of HE}

Many universities consider internationalization as a source of revenue \& as a tool for interconnectedness of HE. Some strategies acknowledge international initiative as a means of earning income to compensate for funding deficits. Recruiting students, establishing new campuses \& implementing other initiatives are strategies to earn revenue. Gornitzka et al. (2008) stated that marketization is an important step for internationalization. However, national autonomy in regard to education is certainly at risk \& closely related to the concerns about the increasing commodification of HE (Altbach et al, 2009). In the name of marketization, fake degrees \& other questionable services are given by some HE institutions. In this regard, Ethiopian distance education offered by HE institutions is an example for its poor quality education (Rumbly et al., 2012). 


\section{International Education Hub}

It is a new development in internationalization of HE representing a new generation of cross boarder educational activities. Critical mass, co-location \& connection between international, national \& local universities, students, \& research institutions \& private industry are the key approaches (Knight, 2013). According to the author, countries such as Hong Kong, Singapore, Malaysia, United Arab Emirate are known for their education hub. There is no single model 'one size fits all' to establish an international education hub. Emphasis on knowledge production \& innovation, twinning, franchising, virtual program delivery, \& branch campuses is some feature of education hub.

\section{Models of Education Hub}

According to knight (2013), student, talent \& knowledge/innovation are the three models of education hub. The student hub is the most focused aiming at increasing access to education for local students, generate revenue from international students, building capacity of local HEIs \& internationalizing domestic HE system. The talent hub emphasis on human resource development by expanding the talent pool of skilled works, building knowledge based economy, increase economic competitiveness, strengthening the quality \& relevance of labor. The specific purpose is Finally, the knowledge hub has mandate including training, production \& distribution of knowledge. Its objectives are build knowledge based economy, attracting foreign direct investment, build local research \& development centers.

\section{International Competition}

International competition has become one of HE internationalization perspectives \& ranking is its manifestation. It brings greater access to funding at all macro, messo \& micro levels (Rumbly et al., 2012). Most of HE institutions highlight the international dimensions in to their profile \& promotional materials. The lists of institutions that now include international in their name is growing. National government actively pursue internationalization goals for competitive purpose that relate to excellence in research, technological innovation, economic strength \& relevance (Rumbly et al., 2012; Jacob \& Meek, 2013). Competition often encourage excellence \& innovation; however, all nations \& institutions risk getting caught up in the powerful forces of international competition without carefully considering what outcomes are truly desired \& achievable.

\section{Cooperative Networking}

Regional \& cross boarder networking are notable aspects of internationalization. Among the manifestations, bologna process can be mentioned. Bologna process attracted the interest of HE leaders \& policy makers \& served as reference point for other regions (Rumbly et al., 2012). In short, cooperative networking \& regionalization are very correlated (Jacob \& Meek, 2013). The establishment of African networking for internationalization of education, the African union harmonization strategies discussions of southeast Asian nations \& Catania declaration are among the cooperative networking works (Rumbly et al., 2012). Joint-degree programs, twinning efforts, \& other approaches to cross-border education provide the promise of expanded capacity-building for under-resourced institutions \& systems (Altbach et al., 2009).

\section{WHAT ARE THE ASSUMED BENEFITS/OPPORTUNITIES, \& THE KNOWN CHALLENGES \& RISKS?}

\section{Opportunities \& Benefits of Internationalization of $\mathrm{HE}$}

The following points imply that internationalization opens many possibilities for $\mathrm{HE}$ institutions \& yield a range of benefits for the broader community. 


\section{Borderless Education, Shared benchmark \& Online Learning}

According to Jacob \& Meek (2013), the impact of globalization on HE offers exciting new opportunities for study \& research no longer limited by national boundaries, \& brings a lot of benefits to the nation like India \& China. Large number of students, countless scholars, degrees, \& universities moving about the globe freely (Altbach et al., 2009). The consequence of economic globalization \& the subsequent pressure on HE to function internationally may be a necessity for effective systems of accountability, shared benchmarks, \& standards for ethics \& quality.

Institutional \& national agendas display international engagement, even in the face of competing priorities (Rumbley, 2007). The growing ease of international travel \& a rapidly expanding IT infrastructure have opened new models for online learning and made education \& resources more readily available to individuals who reside in locations distant from universities. Information technology provides researchers with a broader reach for scholarly collaboration. These expanded opportunities for collegial engagement across borders (Rumbley, 2007 in Altbach et al., 2009).

\section{Building Capacity, New Research Opportunity \& Social Cohesion}

Stakeholders in a variety of regions across the globe are moving toward a shared language \& framework that facilitate the mobility of more \& more students during their studies \& after graduation. International exposure \& experience are mechanisms providing more graduates \& scholars with perspective that will increase their capacity to function in a globalized society (Altbach et al., 2009). It promotes multiculturalism \& cross-cultural awareness \& the impact of internationalization offers new study \& research opportunities (Hénard et al., 2012).

\section{Challenges \& Risks of Internationalization}

Simultaneous to its benefit, the necessity of internationalizing HE to keep pace with economic \& academic globalization brought real risks \& challenges to HE system (Hénard, 2012). At the global level, the three top internationalization risks identified are the accessibility of international opportunities only to students with financial resources, difficulty of regulating locally the quality of foreign programs \& excessive competition among HEIs (European Union, 2015; Altbach et al., 2009). Specifically, the following areas are the challenges \& risks observed in internationalization process of HE.

\section{Unbalanced Resource Background}

To be meaningful \& sustainable, internationalization requires access to some amount of resources as well as their effective deployment \& management. For the world's poorest countries, the opportunities to engage internationally can be extremely limited (Altbach et al., 2009). As a result of their reliance on massive amounts of foreign funding for research \& other activities, unpredictable shift of priorities of foreign donors \& serious disconnection between their priorities \& local needs are taking African universities to be disadvantageous (Teferra, 2008 in Altbach et al., 2009).

\section{Quality of HE}

The mobility of HE programming presents other serious challenges as new providers are crossing national borders with great ease (Knight, 2012). These new cross- border programs typically follow the structure of the provider's home country \& may not be compatible with the education system, cultural norms, or labor- market requirements of the host country. It is often the case that neither the host nor home country has the capacity to monitor the quality, ethics, or conditions of the education being provided. These circumstances increase the urgency of international standards, oversight, \& qualifications frameworks (Altbach et al., 2009). Besides, 
Rumbly, et al. (2012) indicated that uneven playing field create differences in the quality \& quantity of internationalized activities \& outcomes.

\section{Inequality}

International network is interested to draw in members with the best resources to share such as elitist, Northern, \& largely English-speaking paradigms. The students \& scholars most likely to take advantage of the range of new opportunities in a globalized HE environment are typically the wealthiest or otherwise socially privileged. It is highly difficult for poorly resourced institutions to participate/benefit from their out put. For example, most of Africans HE agendas are derived by international donors \& or local stakeholders so that it is extremely complex for African universities, to enter the global HE (Teferra, 2008 in Altbach et al., 2009; Rumbley et al., 2012 \& Altbach et al., 2009).

\section{Language, Cultural Identity \& Ethics}

The use of English as the language of international cooperation shows that international engagement skews priorities towards the most powerful partners. However, it is questionable that country's aspiration to address its challenges such as poverty, unemployment, environmental degradation through the wide spread use of non native language (Rumbly, et al., 2012). Yet, the use of a single language has inevitably limited access to knowledge \& also hinders the pursuit of scholarship in other languages (Altbach, 2004 in Altbach et al., 2009). In Africa, the use of nonnative languages also carries with it the heavy history of colonialism \& has the potential to affect quality in contexts where actors are generally unable to operate with high levels of fluency (Teferra, 2008 in Altbach et al., 2009).

As countries come to offer education in one's country, it brings the experience, norms \& moral aspects of the hosting country. Latin America, the Caribbean, \& the Middle East have been identified as more sensitive to the possible loss of cultural identity through international engagement (Altbach et al., 2009).

Ethics can be perceived in relation to academic freedom, intellectual integrity, communication standards, actors' behavior, respectful treatment of others \& productivity measures (Kenneth, 2002 in Hénard et al., 2012). Ethics underpin the fundamental principles of human relationships \& concern the quality \& the basis for actions (Ismaili et al., 2011 in Hénard et al., 2012). While recognizing that some behavior is ethically acceptable in some countries \& not in others, institutions have faced growing challenges to clearly define ethical standards.

\section{Global Migration of Talents}

Significant growth in numbers of new kinds of providers, notably for-profit companies \& those operating actively in the online environment are noted. However, cross-border arrangements come \& go with some challenges inherent in moving programs \& other institutional activities. It is acknowledged that the international flow of educational programming is highly moving in a North-South direction though there are some exceptions to this rule (Hénard et al., 2012). Limited access to resources \& political constraints may drive scholars from their home country through the procedure of internationalization (Altbach, 2004 in Altbach et al., 2009). A flow of talent South to North \& brain drain in terms of marketization of HE became are key risks of internationalization. Large number of highly educated Ghanian, Chinese, \& others who are living in the wealthier countries can be mentioned ((Sintayehu, 2014; Knight, 2013, Altbach et al., 2009). 


\section{STEP MUST GOVERNMENTS \& HEIS TAKE TO ENHANCE INTERNATIONALIZATION \&} KNOWLEDGE SOCIETY?

\section{Steps must Individual HEIs Take}

Institutions need to keep HE between being a public good \& a tradable service \& ethical requirements should be adjusted accordingly. In each perspective, there are a number of different measures that institutions can consider to enhance their internationalization experience

\section{Considering Ethical Challenges}

Attitudes on ethical questions should involve the wider university community \& national authorities (ministers \& quality assurance agencies). Institutions should reinforce ethical behaviors that would be acceptable across a wide range of HE systems \& need to remain to be forward-looking for foreseeable ethical challenges (Hénard et al., 2012). Strengthening the adequacy, relevance \& good practice of codes of ethics, aligning ethical issues with the quality requirements \& evaluating thoroughly the whole environments are among the steps HE institutions should consider.

\section{Designing Intellectual Property Strategies}

A collaboration agreement, creative work \& knowledge exchange can play a facilitating role without infringing on intellectual property (Altbach et al., 2009). Institutional strategies for internationalization need to fit in with national strategies for the protection \& expansion of intellectual property rights. The intrinsic \& commercial value of discoveries has to be evaluated \& decided whether to enter the patent process. Strong co-operation of institutions with national authorities helps to deal effectively with IP related challenges that could arise from internationalization \& a strategic research relationship could have a governing framework (Hénard et al, 2012; Altbach et al, 2009).

\section{Selecting Strategic Approach to Internationalization}

Internationalization of HE needs selection of appropriate modes/strategies \& forms for the institution, taking both the institution's missions, objectives \& the environment into account. According to Hénard et al. (2012), an institution has to verify that it has the capacities required to support the internationalization strategy, take steps \& incorporate monitoring \& evaluation processes into the strategic plan. Also, institution need to establish the partnerships \& join the international networks that will be most relevant \& effective to achieve the institution's objectives for internationalization. Country-specific objectives of internationalizing HE may include attracting skilled workers, generating revenue, fostering exchange \& co-operation, \& providing cost-effective alternatives to domestic education opportunities (OECD, 2008 in Hénard et al, 2012).

\section{Understanding Context \& Optimizing Implementation}

Internationalization has got a significant profile at the highest level of policy making \& institutional leadership in many corners of the world. Internationalization to bring a positive change, relevance \& quality are quite important. Tangible resources \& informed visions with a strong belief about relevance of internationalization can lead HE leaders \& managers towards success. Leadership of internationalization requires care \& feeding in the form of human, financial \& intellectual resources (Rumbly et al., 2012).

Identifying new issues that can affect the way institutions \& their administrators think about their international profile, learning from the experience of other institutions in implementing different approaches, ensuring the alignment of broader policies with internationalization objectives, communicating the rationale for internationalization to all stakeholders within \& outside the university are among the measures to be taken. (Rumbly et al., 2012). 


\section{Steps must Government Takes}

\section{Steering Internationalization Policy}

A national government is expected to develop a national strategy on internationalization whereby all partners are identified as drivers \&/or beneficiaries. A government can play critical role in the process by designing policy that promotes the build-up of institutional knowledge capacity, internationally oriented scholarly activities, integration of universities in the global HE (Horta, 2010). Aligning internationalization strategies with country specific goals of human capital development (Hénard, 2012).

\section{Understand the Environment Affecting Internationalization}

Objectives of governments \& related actors for internationalization, both in the home country $\&$ in other countries of interest to must be identified. Elements of government policies \& regulatory environments that could impinge on internationalization including public financing, institutional autonomy \& governance, accreditation processes \& qualifications frameworks, visa rules, intellectual property, employment regulations, legal arrangements, expectations of students, geo-political \& economic development trends, opportunities for collaboration in multination context must be analyzed (Hénard et al, 2012).

\section{Monitoring \& Evaluation}

National government must watch out how internationalization is considered in the procedure of HE quality assurance. To assess the effectiveness of internationalization \& to check whether the approach is achieving its objectives, establishing monitoring systems into its strategic plan is crucial (Teichler, n.d). Developing statistical indicators \& surveys to support effective monitoring, incorporating internationalization objectives into the institution's broader quality assurance processes \& student satisfaction need to be worked out (Hénard et al., 2012). The international agendas that survive the pressure of time being effective are those rooted in the mission of the actors involved. Mission, quality \& sustainability are the core elements of control and decision making concerning internationalization. (Rumbly et al., 2012).

\section{CONCLUDING REMARKS}

It has been witnessed a profound \& deepening sense of interconnectedness within the HE enterprise across the globe. Universities, knowledge, academics, students and programs are directly connected to the global knowledge economy. What happens in institutions \& systems in one part of the world has effects on the other. So, university no longer operate in a local context (Hénard et al., 2012). International dimension in HE appears to continue \& to rise in prominence on the agendas of individual institutions, national \& regional systems of tertiary education around the world (Altbach et al., 2009).

As internationalization has risk \& challenges, mismatch $b / n$ international interests \& local need, poor planning \& execution of misguided internationalization strategies, the speed of new development in the current context makes managing internationalization very challenging and opens new opportunities for corruption \& exploitation. Thus, effective internationalization of HE requires unique skills, talents, real vision \& sustained commitment.

\section{References}

Altbach P. G., Reisberg L., Rumbley, L.E. (2009). Trends in Global HE: Tracking an Academic Revolution. Paris: UNESCO. Retrieved from http://www.uis.unesco.org/Library/Documents/trends-global-higher-education-2009world-conference-en.pdf on 12,09,2015

European Union, (2015). Internationalization of HE. Directorate-general for internal policies policy department b: structural \& cohesion policies culture \& education. Retrieved from http://www.europarl.europa.eu/RegData/etudes/STUD/2015/540370/IPOL_STU(2015)540370_EN.pdf on $09,09,2015$ 
Gornitzka, A., Gulbrandsen, M. \& Langfeldt, L. (2008). Crossing the borders: Changing patterns \& forces of internationalization. Spring science \& business media B.V.

Hénard, F. Diamond, L. \& Roseveare, D. (2012). Approaches to internationalization \& their Implications for strategic management \& institutional practice. A guide for HE institutions. OECD HE program IMHE. Retrieved from http://www.oecd.org/edu/imhe/Approaches\%20to\%20internationalisation\%20-\%20final\%20$\% 20$ web.pdf on 10,09,2015.

Horta, H. (2010). The Role of the State in the Internationalization of Universities in Catching-up Countries: An Analysis of the Portuguese HE System. HE Policy 23, 63-81.retrieved from http://www.palgravejournals.com/hep/journal/v23/n1/full/hep200920a.html on 12,09,2015.

Jacob M \& Meek, V.L. (2013). Scientific mobility \& international research network: trends \& policy tools for promoting research excellence \& capacity building. Vol.38, no 3, 331-344.

Knight, J. (2012). Concepts, rationales and interpretive frameworks in the internationalization of higher education. In: Deardorff, D.K., Wit, H.D.,Heyl,J.D., \& Admas, T.(Eds). The SAGE hand book international HE, Pp 2743.

(2013). Education hubs: International, regional \& local dimensions of scale \& scope. Comparative education.49(3) 374-387.

Rumbly, L.E, Albach, P.G. \& Reisberg, L. (2012). Internationalization with in HE context. In deardorff, D.K., Wit, H.D., Heyl, J.D.,\& Adams, T.(Eds.). The SAGE handbook of international HE. pp3-26.

Sintayehu A. (2014). An Appraisal of the Internationalization of HE in Sub-Saharan Africa published in CEPS Journal www.cepsj.si Vol.4| $\mathrm{N}^{\circ} 2 \mid$. Retrieved from http://unike.au.dk/fileadmin/www.unike.au.dk/An_Appraisal_of_Internationalization_of_Higher_Education_in_Su bSaharan_Africa_-_Sintayehu_Alemu.pdf on 17,09,2015.

Teichler, U.(n.d).Internationalization of HE: European Experiences retrieved from http://www.utwente.nl/bms/cheps/summer_school/literature/internationalization.pdf on 16,09,2015. 